T. A. G. M. Huisman

T. Thiel

H. Rumpel

G. Zeilinger

B. Steinmann

E. Martin

\title{
Proton magnetic resonance spectroscopy of the brain of a neonate with nonketotic hyperglycinemia: in vivo-in vitro (ex vivo) correlation
}

G. Zeilinger

Division of Neonatology,

Regional Hospital Aarau, Aarau, Switzerland

\section{H. Rumpel}

Department of Diagnostic Radiology, can be found at http://dx.doi.org/10.1007/s003300101073

T.A.G.M. Huisman ( $)$ T. Thiel

E. Martin

Department of Neuroradiology and Magnetic Resonance,

University Children's Hospital Zurich, Zurich, Switzerland

e-mail: thierry@nmr.mgh.harvard.edu

Tel.: +1-617-7242223

Fax: +1-617-7267422

B. Steinmann

Department of Metabolism and

Molecular Pediatrics,

University Children's Hospital Zurich,

Zurich, Switzerland
Singapore General Hospital, Outram Road, Singapore 169608

Present address:

T. A. G. M. Huisman,

Neuroradiology Section,

MGH-NMR Center,

Massachusetts General Hospital and

Harvard Medical School,

Mailcode CNY 149-2301, Boston,

MA 02119, USA

\section{Eur Radiol (2002) 12:858-861}

We regret that an error occurred in the listing of the names of the authors of this article. The correct listing is as follows:

T.A.G.M Huisman, T. Thiel, H. Rumpel, G. Zeilinger,

B. Steinmann, E. Martin 